\title{
Accidental discovery and isolation of Zika virus in Uganda and the relentless epidemiologist behind the investigations
}

\author{
Hedi Zhou ${ }^{1}$, Bryan Eaton ${ }^{2}$, Zhihong Hu${ }^{1}$, Basil Arif ${ }^{3 凶}$ \\ 1. Wuhan Institute of Virology, Chinese Academy of Sciences, Wuhan 430071, China \\ 2. 6 Belvedere Terrace, Ocean Grove, Victoria 3226, Australia \\ 3. Scientist Emeritus, Laboratory for Molecular Virology, GLFC, Sault Ste. Marie P6A 2E5, Canada
}

\section{INTRODUCTION}

Zika virus (ZIKV) has captured the attention of the world because of its potential to infect neural cells and its teratogenic effects on foetuses and the new born. The virus seems to have various modes of transmission and has been the subject of many reviews in the literature (example, Musso and Gubler, 2016, Wang et al., 2016). ZIKV was first isolated in 1947 but remained almost innocuous causing few and sporadic mild infections until 60 years later when an outbreak occurred in YAP State in the Federal State of Micronesia in 2007 infecting nearly $75 \%$ of the population (Duffy et al., 2009; Ai et al., 2016). A few years later (20132014), there was an epidemic in the islands of French Polynesia located about half way between Mexico and Australia. Almost concomitantly, minor outbreaks occurred in other isolated Pacific islands such as Cook Islands, Samoa, Fiji and New Caledonia. It is truly remarkable how the virus has spread within a short time to these seemingly isolated islands. However, nothing brought ZIKV to the attention of the world more than the horrific images of newborn babies with microcephaly in north eastern Brazil (Adibi et al., 2016, Rubin et al., 2016; Schuler-Faccini et al.,
2016). These images were the impetus for concerted efforts to study viral tropism and to put into motion efforts to combat its spread. The World Health Organization has deemed ZIKV a "public health emergency of international concern" (Cohn J, 2016). The purpose of this manuscript is to review the very early research that led to the discovery and partial characterization of the virus along with some current thoughts and add few personal anecdotes about the scientist who discovered it.

\section{THE FIRST ISOLATION OF ZIKV}

ZIKV (Family Flaviviridae, Genus Flavivirus) was first isolated from and named after Zika forest located parallel to the road from Kampala to Entebbe and along the edge of a long arm of Lake Victoria in Uganda. Initially, two strains of the virus were isolated, one from a sentinel rhesus macaque in 1947 and the second from Aedes africanus mosquitoes in 1948 (Dick et al., 1952). At that time, there was considerable interest in yellow fever in Africa and in 1936, the Rockefeller Foundation established the Yellow Fever Research Institute (YFRI) in Entebbe with a mandate to conduct research on this virus among others. Later, the institute evolved into a top-notch labora- tory on tropical diseases and named the Uganda Virus Research Institute (UVRI) with a much broader mandate. At the center of all that research is Zika Forest, believed to be owned by UVRI (Figure 1).

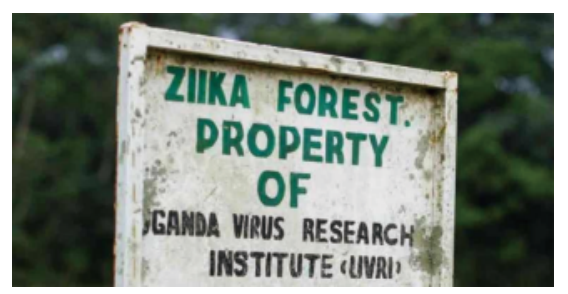

Figure 1. The Uganda Virus Research Institute initially established by the Rockefeller Foundation in 1936.

Because of the prevalence of Yellow Fever Virus (YFV) in the Entebbe peninsula, Zika forest was chosen as the site to isolate strains of the virus. Rhesus monkeys, used as baits for mosquitoes, were placed on platforms and secured on tree canopies in different locations of the forest. The first isolate of ZIKV occurred following infection of one of the sentinel rhesus monkeys (number 766), which fell ill in April, 1947. The animal developed a fever of 40 ${ }^{\circ} \mathrm{C}$ and serum withdrawn during the acute stage caused mortality in Swiss albino mice following intracerebral injection. Interestingly, adult mice 
were refractory to the virus when inoculated intraperitoneally. A Seitz E.K. filterable transmissible agent was isolated from the brains of infected mice and serum withdrawn from the same monkey at the convalescent stage completely neutralized the transmissible agent. Thus, ZIKV was born and named after the forest where it was isolated (Dick et al., 1952). The monkey did not develop a serious illness other than pyrexia. In 1948 a second ZIKV was isolated by an entirely different method. In attempts to isolate strains of YFV from mosquitoes, batches of Aedes africanus were ground in a serum/saline solution, clarified and filtered through Seitz E.K. filter pads. A group of mice was inoculated intracerebrally with unfiltered and filtered suspensions. Evidence showed that a second strain of ZIKV $(E / 1)$ was isolated from infected mosquitoes (Dick et al., 1952). A rhesus monkey 758 was inoculated subcutaneously with E/1 strain but did not exhibit any abnormalities other than a mild elevation in temperature. Serum was taken during the "acute" phase and injected into the brains of six mice demonstrated the virus had multiplied in rhesus 758. Eventually, the monkey developed neutralizing antibodies against ZIKV. Very interestingly, early passages derived from the serum of rhesus 758 caused motor impairment and paralysis in some mice, some of which recovered but infection was usually followed by death. In contrast, acute serum from rhesus 766 produced $100 \%$ mortality in mice (Dick et al., 1952). The authors suggested that paralysis was an example of Theiler's encephalomyelitis. Now we know this to be an error since Theiler's encephalomyelitis virus is a picornavirus and not related to flaviviruses or togaviruses.

In contrast to the bias for nervous tissue in mice, ZIKV was not neurotropic in monkeys, rabbits and guinea pigs (Dick, 1952). However, antibodies have been detected in large animals such as elephants, lions, zebras, some rodents, kangaroos and others (Darwish, 1983; Henderson et al., 1968). It was later demonstrated that while rhesus 758 did not show overt signs of infection, it nevertheless developed neutralizing antibodies against both strains of ZIKV. All cross neutralization tests showed conclusively that ZIKV was not related to YFV, Dengue or to Theiler's murine encephalomyelitis virus. We now know that ZIKV appears to be associated with an autoimmue disease, the Guillain-Barré syndrome where the body's own immunity begins to attack the peripheral nervous system and could lead to motor impairment and paralysis (Hughes and Cornblath, 2005), a fact clearly noted by Dick et al. (1952) in his original publication.

The UVRI built a 35.5 metre tower in the forest to isolate mosquitoes from different levels and, the tower is still standing. The tower has seven dilapidated platforms set perilously over a swamp full of mosquitoes and crocodiles but has been used by scientists for generations to isolate some of the world's most nasty viruses (http://www.theguardian. com/global-development/2016/ feb/13/zika-uganda-world-most-dangerous-viruses-malaria). Investigators went on to isolate no less than 12 strains of ZIKV (Haddow et al., 1964; Haddow and Ssenkubuge 1965) and many of the isolates were from mosquitoes captured after sunset and from above the forest canopy. This was considered an important epidemiological finding since convection currents are quite active at that time of the day and could carry mosquitoes to far locations (Haddow et al., 1964). It is noteworthy that among many viruses isolated by investigators at the UVRI are Yellow Fever, Rift Valley Fever, Bwamba Fever, West Nile, Mengo, Bunyamwera, Ntaya, Uganda S,
Zika Viruses, Chikungunya (CHIKV), Semliki Forest, O'nyong'nyong, Kadam and Entebbe bat viruses (Dick, 1953).

\section{EPIDEMIOLOGY AND DISEASE}

Soon after the first isolation in 1947 , the virus was reported to have infected three people in Nigeria in 1954 (McNamara, 1954). The virus was isolated from one patient and the other two had an upsurge in serum antibodies. However, the first well documented case of ZIKV in man was reported by Simpson (1964) who eloquently described his own infection by the virus. The 28 year old Dr. David Simpson contracted the illness while working at the Entebbe laboratory, Uganda. He took his own serum during the acute febrile phase and inoculated two litters of newborn mice intracerebrally. All the mice died. He then isolated the virus from the brains and showed that it was completely neutralized by anti-ZIKV antiserum.

While interesting and important, these early sporadic and isolated cases of ZIKV infection did not reveal anything extraordinary about the nature of the virus and the disease it causes. It was not until 2007 (60 years after the first isolate) that, now the well-known outbreak occurred in YAP State of Micronesia when nearly $75 \%$ of the small population contracted the virus (Duffy et al., 2009; Ai et al., 2016). This was followed by a major outbreak in French Polynesia such as Tahiti and Moorea in 2013-2014. Other outbreaks continued to appear in many Pacific and South Pacific islands (Ai et al., 2016). To date, more than 50 countries harbour the virus. However, none of these outbreaks made a major impact until the world was shocked by the appearance of the virus in north eastern Brazil with mothers giving birth to babies with microcephaly (Heymann et al., 2016; Broutet, 2016; Ventura, 2016a, 2016b). 
Originally, it was not clear if ZIKV targeted developing foetal brain cells or even infects other neural cells. To resolve this dilemma, investigators induced pluripotent stem cells to form human neural progenitor cells, hNPCs (Tang et al., 2016) and found that the original ZIKV strain isolated from rhesus 766 efficiently infected hNPCs. They concluded that the virus targets these cells directly. The investigators conducted a global transcriptome analysis and found that upon virus infection, there was a significant number of differentially expressed genes with up-regulation of a large number of genes involved in transcription, protein transport and catabolic processes. Concomitantly, there was a significant downregulation of genes related to cell cycle pathway (Tang et al., 2016). This was the first evidence that ZIKV targeted neural cells.

With all the above solid evidence plus numerous seminal observations, it was still not possible to conclude that ZIKV is the causative agent of microcephaly and/or Guillain-Barré syndrome. However, evidence has been mounting at a lightning speed and after thorough and careful examination of all the existing evidence, the Centers for Disease Control and Prevention in the US has clearly concluded that ZIKV is the causative agent of microcephaly (http://www.cdc. gov/media/releases/2016/s0413-zikamicrocephaly.html). They also indicated that this could be the tip of the iceberg in terms of damaging effects on the brain with other neurological manifestation. Having established the cause and effect relationship between ZIKV and foetal brains, the $\mathrm{CDC}$ believes that their research should drive further efforts to control the spread of the disease.

\section{FROM DORMANCY TO EPIDEMIC}

It is, indeed, enigmatic that a virus, which was innocuous for 60 years, as exhibited by its limited geographic distribution and paucity of human cases suddenly appears in 2007 as the cause of a human epidemic in Yap State of Micronesia. Since then, the virus continued to spread to other parts of the world until its alarming manifestation in Brazil. The question is what happened to cause a relatively harmless virus suddenly appear in such a malevolent capacity. The answer has not yet been elucidated and, most likely several factors such as viral, vectorial, environmental, etc. must have played significant roles in its resurgence. If one looks at the epidemiologic history of another mosquito-borne virus, Chikungunya (CHIKV, Alphavirus, Togaviridae) also isolated at the UVRI, we see that it was innocuous until 2005 when it started an epidemic in Reunion Island (Chastel, 2005; Enserink, 2006; Ligon, 2006). The island is located in the Indian Ocean just east of Madagascar and south of Mauritius. Within two years starting in 2005 , the virus caused an epidemic that infected more than a third of the population in Reunion Island with 260 deaths (Simon et al., 2007). Prior to this, CHIKV was not known to cause death in humans, then was transformed from nearly harmless to deadly. In comparison to the east African strain, the virus from Reunion Island had a single mutation of A226V in the envelope E1 protein (Tsetsarkin et al., 2007). Detailed analyses showed that this single mutation influenced vector fitness and viral infectivity. CHIKV is normally harboured and transmitted by Aedes aegypti but this one mutation allowed the virus to be carried by and multiply in the Asian tiger mosquito, Aedes albopictus, which is known for its anthropophylic bias and exists in many countries in Europe and North America. Certainly, this adaptive evolution allowed the virus to rapidly expand its geographic distribution. As of 2007, at least 1.4 million people have been infected with CHIKV (Ravi 2006; Pialoux et al., 2007). It is very tempting to speculate that a mutation(s) in ZIKV E protein might have contributed to the geographic explosion of virus since 2007. Recently, phylogenetic analyses have shed much light on the movement and migration of ZIKV among different countries. Initially, two phylogenetic lineages, the Asian and the African were identified based on the availability of rather limited genomic sequences (Haddow et al., 2012). More recently, phylogenetic analyses based on all available viral sequences including the open reading frames (ORFs) encoding the envelope E protein and the non-structural protein NS5 resolved three lineages identified as the African 1, African 2 and Asian/ American (Shen et al., 2016). The latter study elucidated the central role of two Western African countries, Senegal and Cote d'Ivoire in the evolution of ZIKV and the viruses that caused the outbreaks in Asia and the Pacific islands were born in Western Africa.

\section{WHAT IS NEXT?}

Prevention measures to stop the spread of ZIKV are no different than any others in the control of mosquitoborne viral disease. They include the obvious control of mosquitoes in their breeding ponds and the use of personal insect repellents. We also know that it is transmitted sexually so strict precautions in this regard will have to be taken (Cooke, 2016). Anti-viral drugs would be the choice option since the virus is spreading at such a rapid rate and with adverse consequences. Many antiviral drugs have proven to be quite effective but they need to affect virus replication negatively without major toxicity to the cell. Many flavivirus drug targets have been identified and many appear to be promising (Sampath and Radmanabhan, 2009). Molecular, structural and biochemical characterization of many vital viral pro- 
teins is a prerequisite to identifying small molecules to target essential steps in virus replication. The flavivirus RNA dependent RNA polymerase (RdRp) may turn out to be an excellent target. Random screening of nucleoside analogues identified several adenine derivatives that were effective inhibitors of RdRp with negligible cell toxicity (Angusti et al., 2008). Virus entry into cells is another target that can be exploited to prevent virus replication. Such a target was an excellent choice in fighting HIV-1 infection (Citterio and Rusconi, 2007; Munch et al., 2007).

A unique anti-flavivirus inhibitor was discovered when high throughput screening of nearly 240,000 compounds for small molecular inhibitors of the non-structural protein 5 (NS5) of DENV. NS5 is the RNA capping enzyme (Stahla-Beek et al., 2012) in flaviviruses. The investigators identified a number of compounds with powerful capacity to inhibit GTP binding and Guanylyltrasferase activity of NS5. These compounds exhibited profound antiDENV activity and also had a partially negative effect on the replication of YFV and West Nile virus (Stahla-Beek et al., 2012). Naturally, the development of an anti-ZIKV vaccine much like the one developed against yellow fever virus would be a very good long term mitigation measure. One avenue that promises success has been reported recently (Shan et al., 2016) where the investigators generated an infectious RNA derived from a cDNA clone. A full length transcript of the cDNA clone was infectious to Vero cells and generated a virus infectious to mice by the intracerebral route and also replicated in Aedes aegypti. The authors went on to generate a luciferase-marked virus for use in drug screening and other downstream options (Shan et al., 2016). They indicated that this system of reverse genetics along with the mosquito and mouse models may help explain virulence of ZIKV to humans and may aid in the design of intelligent strategies to generate effective drugs and vaccine.

A novel and audacious genetic control strategy was developed at Oxford Insect Technologies. By introducing fatal genes into male $\mathrm{Ae}$ des aegypti mosquitoes, they genetically modified the insect to produce progeny that get killed before reaching adulthood (Oxitec mosquitoes known officially as OX513A, Oxitec.com). This depends on the fact that the main purpose in life of a male mosquito is to find a female to mate and produce progeny. Evidently, this is a different model from other genetic strategies. Saturating a dense urban environment with Oxitec mosquitoes should, theoretically, drastically reduce the progeny from wild-type Aedes aegypti. The approach is unique because it is selflimiting with no residue left in the environment. Essential to note that Brazil has an enormous water system in the Amazon ideal for mosquito breeding where Oxitec mosquitoes may not be a viable control option.

One cannot help but mention the summer Olympics scheduled in Brazil in August with the expected influx of hundreds of thousands of people. No doubt, a large number will be infected with ZIKV and will transport it back to their home countries. We might expect to see another spike in the ZIKV infection rate in the world. Indeed, at these Olympics, ZIKV could be the most decorated athlete.

\section{THE SCIENTIST}

This manuscript is as much about the discovery of ZIKV as it is about the famous Virologist/Epidemiologist, George W. Dick (Figure 2), who discovered it in 1947 while working as a research scientist at YFRI in Entebbe, Uganda. In 1939, he joined

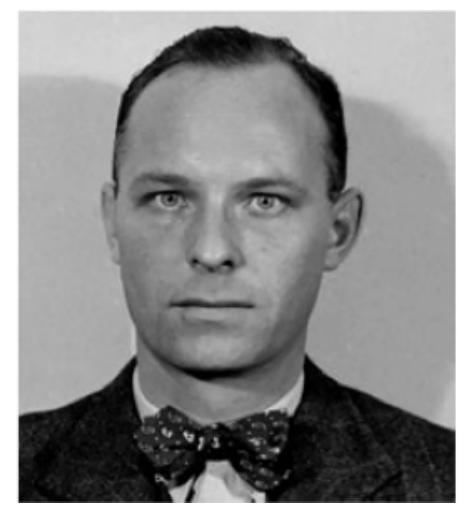

Figure 2. Prof. George W. Dick (Aug. 14, 1914-July 3, 1997), the Epidemiologist/Virologist who first isolated ZIKV. (Courtesy of Prof. George W. Dick)

the British Royal Army Medical Corps and was sent to East Africa to be in charge of the army's pathology services. After the Second World War, he became a Fellow of the Rockefeller Foundation with appointments at the John's Hopkins University (JHU) in Baltimore, USA and a Fellow of the School of Hygiene and Public Health of the JHU but remained in Uganda working at the YFRI. For about five years he focused on the natural history of yellow fever virus. In 1950 following his return to England for a position at the Medical Research Council, George Dick then accepted a professorship and became the Chairman of the Department of Microbiology at Queen's University of Belfast in 1955. In addition to being a brilliant investigator, Prof. Dick was distinguished as a mentor and educator of a number of young scientists who went on to develop careers of their own in microbiology and virology. Two of the authors (B. Eaton and B. Arif) were fortunate to be two of three students studying honours microbiology (1963-1967) at that time at the Queen's University of Belfast and received much attention and personalized training from Prof. Dick and all the professors at the department. Indeed, Prof. Dick's 
virology lectures, which were held in his office often extended from the mandatory hour to 3 or more hours. He was an enthusiastic and inspiring professor and one of the few scientists who instilled into us the passion for the science of virology that remained with us throughout our careers. Herewith a humorous anecdote: in describing his experiences in Africa he recalled how human volunteers captured mosquitoes with test tubes while sitting lightly clad on a tree branch in Zika forest.

George Dick was also recognized for his stellar work on poliomyelitis in Mauritius, his research on Yellow Fever and other tropical diseases in Entebbe, Uganda and for his work on hepatitis in mice while at the Medical Research Council in Millhill, England. In the 1950s at Queen's University, he expended most of his efforts on the development of an attenuated live poliovirus vaccine for the United Kingdom. Being a scientist in the purest sence and a member of the "old school", he inoculated himself with the experimental vaccine before administering it to any volunteer. He was so confident of the vaccine that his family was next in line to receive the vaccine. Eventually, he became the leading authority on vaccines in the United Kingdom. We (BA and BE) remember him well when the British Broadcasting Corporation (BBC) requested him to give a series of TV presentation in Britain on Viruses and Vaccines. His scientific notoriety reached far and wide and served as an advisor and examiner at medical schools in the UK, Ireland, Nairobi, Kampala, Cape Town, Riyadh and Jeddah.

On one well remembered occasion Prof. Dick said to us students "As a scientist, it is your mission to add a brick in the wall of science". We wish Prof. Dick was alive to take the credit for the addition of a brick called Zika virus, to the wall of sci- ence.

One of us (BE) wishes to acknowledge Prof. Dick's instrumental role in getting funding at a time when the British system provided allowances for university students pursuing their first degree. As a student who had already graduated with a BSc (hons) in Chemistry, BE was not eligible for further support to acquire a BSc (hons) in Microbiology. Prof. Dick ensured the funding became available.

Interestingly, Dr. David Simpson was also a member of the Department of Microbiology in Belfast when we were there and relayed many of his fascinating experiences in Africa but we did not know at that time he was the first well documented human case of ZIKV infection (Simpson, 1964).

This article was written because of the fond memories two of the authors (BE, BA) have of Prof. George W. Dick.

\section{$\triangle$ Correspondence:}

Phone: 1-705-541-5512,

Email: basil.arif@canada.ca,

ORCID: 0000-0002-7421-1842

Published online: 18 July 2016

\section{REFERENCES}

Adibi JJ, Marques Jr ETA, Cartus A, et al. 2016. The Lancet. 387: 1587-1590.

Ai JW, Zhang Y, Zhang W. 2016. Emerging Microb Infect. 5: e21.

Angusti A, Manfredini S, Durini E, et al., 2008. Chem Pharm Bull, 56: 423-432.

Broutet N, Krauer F, Riesen M, et al. 2016. New Eng J Med, 374: 1506-1509.

Chastel C. 2005. Bull Acad Natl Med, 189: $1827-1835$.

Cittero P, Rusconi S. 2007. Expert Opin Investig Drugs, 16: 11-23.

Jonathan Cooke, J. 2016. Lancet Infect Dis, 16: 405.

Darwish MA, Hoogsraal H, Roberts TJ, et al. 1983. Trans R Soc Trop Med Hyg, 77: 442445 .

Dick GWA. 1952. Trans Roy Soc Trop Med
Hyg, 46: 521-534.

Dick GW, Kitchen SF, Haddow AJ. 1952. Trans R Soc Trop Med Hyg, 46: 509-520.

Dick GWA. 1953. Trans R Soc Trop Med Hyg, 47: 13-43.

Duffy MR, Chen TH, Hancock W, et al. 2009. New Eng J Med, 360: 2536-2543.

Enserink M. 2006. Science, 311: 1085.

Calvet G, Aguiar RS, Melo AS, et al. 2016. The Lancet, 16: 653-660.

Haddow AJ, Ssenkubuge Y. 1965. Trans R Entomol Soc London, 117: 215-243.

Haddow AJ, Williams MC, Woodall JP, et al. 1964. Bull Wld Hlth Org, 31: 57-69.

Haddow AD, Schuh AJ, Yasuda CY, et al. 2012. PLoS Negl Trop Dis, 6: 1-7.

Henderson BE, Hewitt LE, Luke M. 1968. Virus Research Institute Annual Report. Nairobi: East African Printer, pp48-51.

Heymann DL, Hodgson A, Sall AA, et al. 2016. Lancet; 387: 719-721.

Hughes RAC, Cornblath DR. 2005. The Lancet, 366: 1653-1666.

Ligon BL. 2006. Semin Pediatr Infect Dis, 17: 99-104.

Lopes R J. 2016. Nature News, doi:10.1038/ nature.2016.19804.

MacNamara FN. 1954. Trans R Soc Trop Med Hyg, 48: 139-145.

Münch J, Ständker L, Adermann K, et al. 2007. Cell, 129: 263-275.

Musso D, Gubler DJ. 2016. Clin Microbiol Rev, 29: 487-524.

Pialoux G, Gaüzère BA, Jauréguiberry S, et al. 2007. Lancet Infect Dis, 7: 319-327.

Ravi V. 2006. Indian J Med Microbiol, 24: 83-84.

Rubin EJ, Michael F, Greene MF, et al. 2016. New Engl J Med, 374: 984-985.

Sampath A, Padmanabhan R. 2009. Antiviral Res, 81: 6-15.

Schuler-Faccini L, Ribeiro EM, Feitosa IM, et al. 2016. MMWR Morb Mortal Wkly Rep, 65: 59-62.

Shan C, Xie X, Muruato AE, et al. 2016. Cell Host Microbe, 19: 1-10.

Shen S, Shi J, Wang J, et al. 2016. Virol Sin, 31: 118-130.

Simpson DIH. 1964. Tras Roy Soc Trop Med Hyg, 58: 335-338.

Simon F, Parola P, Grandadam M, et al. 2007. Medicine (Baltimore), 86: 123-137.

Tang H, Hammack C, Ogden SC, et al. 2016. Cell Stem Cell, 18: 1-4.

Tsetsarkin KA, Vanlandingham DL, McGee CE, et al. 2007. PLoS Pathogen, 3: 1895-1906.

Ventura CV, Maia M, Bravo-Filho V, et al. 2016a. Lancet, 387: 228.

Ventura CV, Maia M, Ventura BV, et al. 2016b. Arq Bras Ofalmol, 79: 1-3.

Wang Z, Wang P, An J. 2016. Virol Sin, 31: 103-109. 